\title{
Regional gray matter density is associated with morningness- eveningness: evidence from voxel-based morphometry
}

Hikaru Takeuchi ${ }^{a}$, Yasuyuki Taki ${ }^{\mathrm{a}, \mathrm{b}, \mathrm{c}}$, Atsushi Sekiguchi ${ }^{\mathrm{b}, \mathrm{d}}$, Rui Nouchie ${ }^{\mathrm{e}}$, Yuka Kotozaki ${ }^{\mathrm{f}}$, Seishu Nakagawa ${ }^{\mathrm{d}}$, Carlos Makoto Miyauchi ${ }^{\mathrm{d}}$, Kunio Iizuka ${ }^{\mathrm{d}}$, Ryoichi Yokoyama ${ }^{\mathrm{d}, \mathrm{g}}$, Takamitsu Shinada ${ }^{\mathrm{d}}$, Yuki Yamamoto ${ }^{\mathrm{d}}$, Sugiko Hanawa ${ }^{\mathrm{d}}$, Tsuyoshi Arakif, Hiroshi Hashizume $^{\text {a }}$, Keiko Kunitoki ${ }^{\text {h }}$, Yuko Sassa ${ }^{\text {a }}$, Ryuta Kawashima ${ }^{\text {a,d,f }}$

aDivision of Developmental Cognitive Neuroscience, Institute of Development, Aging and Cancer, Tohoku University, Sendai, Japan

${ }^{b}$ Division of Medical Neuroimaging Analysis, Department of Community Medical Supports, Tohoku Medical Megabank Organization, Tohoku University, Sendai, Japan

cDepartment of Radiology and Nuclear Medicine, Institute of Development, Aging and Cancer, Tohoku University, Sendai, Japan

dDepartment of Functional Brain Imaging, Institute of Development, Aging and Cancer, Tohoku University, Sendai, Japan

eHuman and Social Response Research Division, International Research Institute of Disaster Science, Tohoku University, Sendai, Japan

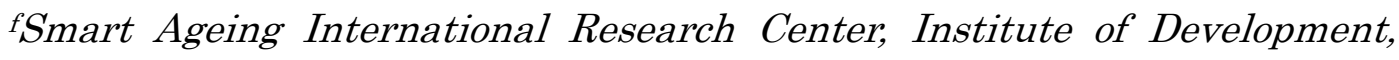
Aging and Cancer, Tohoku University, Sendai, Japan gJapan Society for the Promotion of Science, Tokyo, Japan

${ }^{g}$ Faculty of Medicine, Tohoku University, Sendai, Japan

\section{Corresponding author:}

Hikaru Takeuchi 
Division of Developmental Cognitive Neuroscience, IDAC, Tohoku University

4-1 Seiryo-cho, Aoba-ku, Sendai 980-8575, Japan

Tel/Fax: +81-22-717-7988

E-mail: takehi@idac.tohoku.ac.jp

Short title: Morningness-eveningness and gray matter structure

Keywords: chronotype, voxel-based morphometry, brain structure, precuneus, orbitofrontal cortex 


\begin{abstract}
Diurnal preference (morningness-eveningness) is known to be associated with several individual characteristics that are important in the fields of sociology, education, and psychiatry. Despite this importance, the anatomical correlates of individual differences in morningness-eveningness are unknown, and these were investigated in the present study. We used voxel-based morphometry and a questionnaire to determine individual morningness-eveningness and its association with brain structures in 432 healthy men and 344 healthy women (age, $20.7 \pm 1.8$ years). We demonstrated that morningness (less eveningness) was associated with (a) lower regional gray matter density (rGMD) in the precuneus and adjacent areas, (b) lower rGMD in the left posterior parietal cortex and adjacent areas, and (c) higher rGMD in the bilateral orbitofrontal cortex. Further, our exploratory analyses revealed that (d) higher rGMD in hypothalamic areas around the bilateral suprachiasmatic nuclei was associated with morningness. These findings demonstrate that variations in morningness-eveningness reflect the GM structures of focal regions across the cortex, and suggest a structural basis for individual morningness-eveningness and its association with a wide range of psychological variables distributed across different GM areas of the brain.
\end{abstract}




\section{Introduction}

The continuum of diurnal preference or "morningness-eveningness" refers to individual differences in the timing of circadian sleep-wake cycles and subjective alertness throughout the day (Killgore and Killgore, 2007). It has been suggested that approximately $50 \%$ of individual variability in morningness-eveningness is affected by genetic factors (Hur and Lykken, 1998) including polymorphisms in circadian clock-relevant genes (Takahashi et al., 2008), suggesting the robust innate basis of this measure. The negative feedback loops associated with the expression of these genes form the circadian rhythm (e.g., Darlington et al., 1998; Jin et al., 1999) and polymorphisms in these genes affect the length of circadian rhythms (e.g., Katzenberg et al., 1998). These genes are widely expressed, but particularly enriched in the suprachiasmatic nucleus, and neuronal activity in this area plays a central role in coordinating circadian rhythms (Inouye and Kawamura, 1982). Performance and neural activity changes in this area, which are related to interactions between time of day and morningness-eveningness, have been previously investigated in humans (Schmidt et al., 2009).

There are several measurements of morningness-eveningness. One of the representative meth The most widely used instrument is the Morningness-Eveningness Questionnaire (MEQ), which is a self-report measure (Horne and Ostberg, 1976). We focused on this scale in the present study. This scale contains questions about feelings and behaviors that are related to sleep, peak performance, and other circadian functions. The reliability of MEQ, as measured by Cronbach's coefficient of alpha was .89 . Moreover, MEQ has been shown to be a valid indicator of circadian arousal (Smith et al., 1989), and a higher MEQ score has been shown to be associated with an earlier time 
of the lowest body temperature (Baehr et al., 2000) as well as an earlier time of waking (Baehr et al., 2000) and a shorter intrinsic circadian period (Duffy et al., 2001), as predicted theoretically. These findings demonstrate the criterion-related validity of the test. In addition, it should be noted that the MEQ score and the concept of morningnesseveningness reflect not only circadian processes but also homeostatic processes (Mongrain et al., 2006). For example, subjects with morningness tend to show faster dissipation of sleep pressure during sleep, while buildup of sleep pressure during wakefulness is slower in subjects with eveningness (Mongrain et al., 2006; Taillard et al., 2003).

On the other hand, it is also well established that there is another aspect to individual characteristics of morningness-eveningness that exists regardless of the time of day. First, morningness-eveningness has been associated with biological factors such as sex (Adan and Natale, 2002) and age (Randler and Saliger, 2011). These are biological factors that are likely to affect morningness-eveningness. Morningness has also been associated with personality and temperament, especially cognitive components associated with self-discipline and pro-social behaviors such as high conscientiousness, high self-directedness, low impulsiveness, and high cooperativeness and agreeableness (Lee et al., 2012; Randler, 2008; Randler and Saliger, 2011). At least some of these factors, particularly those related to discipline, may be associated with morningness because a well-disciplined lifestyle may lead to morningness (Díaz-Morales et al., 2008). Second, eveningness has been associated with greater higher-order cognitive abilities such as higher psychometric intelligence and higher working memory capacity even when these are assessed in the morning (Piffer et al., 2014; Roberts and Kyllonen, 1999) despite low academic performance (Díaz-Morales 
and Escribano, 2013; Randler and Frech, 2006). The causal mechanisms underlying these associations are not clear; however, one speculation is that a third factor such as the basic arousal level leads to both higher cognitive abilities and eveningness. Third, eveningness has been associated with traits or states linked to worse mood such as higher harm avoidance, higher neuroticism, and more suicide attempts (Lee et al., 2012; Randler, 2008; Randler and Saliger, 2011; Selvi et al., 2011). These may partly be consequences of eveningness in modern life. For example, eveningness is associated with insufficient sleep (Taillard et al., 1999), which in turn may lead to a chronic bad affective state (Akashiba et al., 2002). In addition, insufficient sleep and the fact that tests and classes are held earlier in the day at school may underlie the low academic performance (Díaz-Morales and Escribano, 2013), which in turn may lead to a bad affective state. These emotional problems in eveningness may underlie their low pro-sociality, which is described above, because well-being and pro-sociality have a close positive relationship (Strayer and Roberts, 2004; Takeuchi et al., 2014a). Finally, perhaps because of sleep and emotional problems, eveningness has also been associated with attentional and behavioral problems in everyday life (Baird et al., 2012; Gau et al., 2007; Susman et al., 2007).

Thus, morningness-eveningness is an essential characteristic of individuals. It is related to a wide range of individual characteristics that are important in society, education and clinical areas such as academic performance, aging, sex, and traits and states associated with psychiatric disorders and social cognition. However, despite the unique importance of the morningness-eveningness construct, the anatomical basis of the aspects of morningness-eveningness that are related to a wide range of stable abilities and traits of individuals is unknown. 
We hypothesized that increased morningness is associated with the following various brain structures in young adults by considering the wide range of psychological correlates of morningness-eveningness. (A) Less gray matter (GM) structures in the precuneus, medial prefrontal cortex, and adjacent regions, which are structurally associated with pro-social (Banissy et al., 2012; Coutinho et al., 2013; Hu et al., 2011; Takeuchi et al., 2014b) and self-disciplinary cognitive components (Gardini et al., 2009; Takeuchi et al., 2011g) and functionally associated with inference of mind, both of one's own mind and that of others (Ochsner et al., 2004); (B) Larger or less GM structures in the anterior brain regions including the medial prefrontal cortex, orbitofrontal cortex (OFC), lateral prefrontal cortex, and anterior cingulate cortex, which are associated with higher-order cognitive functions; (C) Less GM structures in areas associated with states or traits linked to negative mood, such as the amygdala/hippocampal areas (Iidaka et al., 2006; Yamasue et al., 2008), insula (Takeuchi et al., 2014b); (D) Larger GM structures in some of the abovementioned areas and the posterior parietal cortex (PPC), which are liked to attentional problems in everyday life (Kanai et al., 2011).

To test these hypotheses, we investigated how individual differences in morningness-eveningness were associated with regional GM density (rGMD) using voxel-based morphometry (VBM) (Good et al., 2001) after controlling for age, sex, general intelligence, and total intracranial volume.

As described in our previous study (Takeuchi et al., 2012c), functional imaging and structural studies have advantages and disadvantages, and they can be useful in different situations. Here, structural imaging studies are especially useful for investigating the aspects of morningness-eveningness that are related to a wide range of stable abilities and traits of individuals. This is because unlike the results of functional 
magnetic resonance imaging (fMRI) studies, the results of structural imaging studies are not likely to be affected by the time of day. Furthermore, in MRI correlation studies (including those of fMRI) that investigated the neural basis of individual differences, we are able to use established cognitive measures with proven reliability and validity to tap individual differences in cognition. As summarized in our previous study (Takeuchi et al., 2012b), GM in VBM is thought to reflect the number and size of neurons and glial cells, the synaptic bulk, and the number of neurites (May and Gaser, 2006; Takeuchi et al., 2011f). However, this idea remains to be proven by histological studies. The rGMD has also been associated with specific individual personality (trait) characteristics (e.g., Haier et al., 2004; Kanai et al., 2011; Takeuchi et al., 2010b; Takeuchi et al., 2013c). Structural imaging thus provides unique information about the neural origin of morningness-eveningness. Automated VBM yields data comparable to that of manual region of interest (ROI)-based analyses (Testa et al., 2004). Recent advancement of preprocessing methods, including segmentation using more tissue classes, and diffeomorphic anatomical registration using diffeomorphic anatomical registration through exponentiated lie algebra (DARTEL) methods have further improved the accuracy of results and achieved more precise inter-subject registration of brain images (Klein et al., 2009; Peelle et al., 2012).

\section{Methods}

Subjects

Seven hundred and seventy-six healthy, right-handed individuals (432 men and 344 women; $20.7 \pm 1.8$ years) participated in this study. Subjects participated in this study as part of an ongoing project investigating associations among brain imaging, cognitive 
functions, aging, genetics, and daily habits (Takeuchi et al., 2010a, b; Takeuchi et al., 2011a, b; Takeuchi et al., 2011f; Takeuchi et al., 2012c; Taki et al., 2010; Taki et al., 2011). Data derived from the subjects in this study are to be used in other studies irrelevant to the theme of this study. Some of the subjects who participated in this study also became subjects of intervention studies (psychological and imaging data recorded before the intervention were used in this study)(Takeuchi et al., 2013b). Psychological tests and MRI scans not described in this study were performed together with those described in this study. All subjects were university, college, or postgraduate students or subjects who had graduated from these institutions within 1 year before the experiment and had normal vision. The subjects were recruited by advertisements introducing the study that were posted on bulletin boards at the Tohoku University or sent to potential subjects via email. These advertisements and emails also specified the study's exclusion and inclusion criteria. Exclusion criteria included handedness (left-handedness), the existence of metal implants in and around the body, claustrophobia, use of certain drugs (antipsychotic drugs, illicit psychoactive drugs, other drugs for psychiatric and neurological disorders prescribed by doctors, and others), a history of certain psychiatric or neurological diseases, and previous participation in related experiments. We provided self-report questionnaires to each potential subject to assess their history of psychiatric illness and recent drug use. The questionnaires required subjects to provide a detailed list of any recent drug use. Thus, no study subject had neurological or psychiatric illnesses. The assessments performed during and after recruitment were all voluntary self-reports. Handedness was evaluated using the Edinburgh Handedness Inventory (Oldfield, 1971). Shift work and recent transmeridan travel have not been considered in exclusion criteria. However, the subjects were all students and most had to attend 
classes regularly early in the morning. As they are students, they do not go abroad very often. They were informed of the study on campus and given preliminary explanations several days before testing (MRI and psychological tests). Although we cannot control for all experiences, we believe subjects who have effects of "jet lag" are unlikely and scarce at most. As per the Declaration of Helsinki (1991), written informed consent was obtained from each subject prior to MR scanning after a full explanation of the purpose and procedures of the study was provided. Approval for these experiments was obtained from the Institutional Review Board of Tohoku University.

$M E Q$

The Japanese version (Ishihara et al., 1986) of MEQ (Horne and Ostberg, 1976) was used to assess individual morningness-eveningness. The scale contains 19 items. The answers to these questions are compiled into a single score. A higher score indicates morningness.

Based on the MEQ score, subjects were divided into five groups (70-86, definitely morning type; 59-69, moderately morning type; 42-58, intermediate type; 31-41, moderately evening type; 16-30, definitely eveningness type) or three groups (59-86, morning type; 42-58, intermediate type; 16-41, evening type) (Horne and Ostberg, 1976; Ishihara et al., 1986). Because of the fact that definitely types are scarce and following the custom of the field, three-group classification was used in analyses, in addition to the MEQ score.

Psychological measures of cognitive functions.

To assess morningness-eveningness related cognitive functions, Raven's 
Advanced Progressive Matrix (RAPM; Raven, 1998) was used to assess intelligence and adjust for the effect of general intelligence on brain structures (Haier et al., 2004). For more details on how RAPM was administered, refer to our previous study (Takeuchi et al., 2010b, c). The Tanaka B-type intelligence test (for details, see Takeuchi et al., 2011d), which calculates intelligence from several speeded tasks, was also used to measure psychometric intelligence. Computerized visuospatial and digit span tasks were used to assess visual and verbal working memory performance (for details, see Takeuchi et al., 2011d, e). Creativity measured by divergent thinking has been previously reported to be marginally significantly associated with eveningness in a previous study of a relatively small number of subjects; therefore, we also employed a measure of creativity on the basis of divergent thinking (S-A creativity test, for details see Takeuchi et al., 2010b, c). Among 776 subjects, the performance of 266 subjects (135 males, 131 females) was assessed in the morning (approximately 9:00-12:30), the performance of 375 subjects (208 males, 167 females) was assessed in the afternoon (approximately 13:15-16:45), and the performance of the remaining 135 subjects (89 males, 46 females) was assessed in the evening (approximately 17:00-20:30).

Subjects were instructed to get sufficient sleep, maintain their conditions, eat sufficient breakfast, and to consume their normal amounts of caffeinated foods and drinks in the day of cognitive tests and MRI scans. In addition, subjects were instructed to avoid alcohol the night before the assessment.

\section{Psychological measures assessed by questionnaire}

To assess temperament and character, a Japanese version (Kijima et al., 1996) of the Temperament Character Inventory (Cloninger et al., 1993) was used. To assess 
attentional problems in everyday life, we used the concentration subscale of the Checklist Individual Strength (CIS) questionnaire (Aratake et al., 2007). To assess suicide-related measures, we used the suicide ideation subscale of the General Heath Questionnaire 30 (Iwata et al., 1994).

\section{Image acquisition}

All MRI data acquisition was performed using a 3-T Philips Achieva scanner. High-resolution T1-weighted structural images (T1WIs: $240 \times 240$ matrix, TR $=6.5 \mathrm{ms,}$ $\mathrm{TE}=3 \mathrm{~ms}, \mathrm{FOV}=24 \mathrm{~cm}$, slices $=162$, slice thickness $=1.0 \mathrm{~mm}$ ) were collected using a magnetization-prepared rapid gradient echo sequence. MRI data was acquired during the time span of 8:00 AM to 9:00 PM. We could not control the time of the scan considering the limitation of the MRI use and the fact in a scanner, only one subject' image can be taken at a time. We did not model the time of the scan partly because there is no evidence to make us assume that can affect the individual brain structure and partly because it is difficult to model the potential non-linear interaction effects between morningness-eveningness and time of the scan.

\section{Preprocessing of T1-weighted structural data}

Preprocessing of the structural data was performed using Statistical Parametric Mapping software (SPM8) using new segmentation methods in SPM8 and through DARTEL registration process implemented in SPM8. Subsequently, all images were smoothed by convolving them with an isotropic Gaussian kernel of 12-mm full width at half maximum (FWHM) for the reasons described below. The Jacobian modulation(Ashburner and Friston, 2000) was not applied and thus the images represent 
rGMD. However, to assess the associations between rGMD in the suprachiasmatic nucleus, which is a small nucleus, and morningness-eveningness, we smoothed images by convolving them with an isotropic Gaussian kernel of 3-mm FWHM. For more details, of procedures and why 12-mm FWHM smoothing had to be used, see

\section{Supplemental Methods.}

\section{Statistical analyses of psychological data}

First, the associations between morningness-eveningness and other psychometric tests were investigated using multiple regression analyses across all participants regardless of the time of the tests. In these analyses, the MEQ score was the dependent variable and independent variables included age, sex, and one of the following: Raven's Advanced Progressive Matrix test, Tanaka B-type intelligence test, visual working memory test, verbal working memory test, S-A creativity test, Novelty seeking, Harm avoidance, Reward dependence, Persistence, Self-directedness, Cooperativeness, and Self-transcendence. We also performed multiple regression analyses with only age and sex to examine their independent effects on morningnesseveningness. In addition, we analyzed the relationships of morphometric results to performance-type cognitive parameters using only test scores obtained in the morning (Piffer et al., 2014; Roberts and Kyllonen, 1999) to assess if the strength of associations differed substantially based on the test time. Finally, to assess the effects of chronotype, test time, and their interaction on performance-type cognitive tests, we performed analyses of covariance (ANCOVAs). In these analyses, sex, time of day, and chronotype were fixed factors and age was a covariate. ANCOVA models included all these variables as well as the interaction between time of day and chronotype. Dependent 
variables were the scores on individual performance-type cognitive tests.

Moreover, to compare the performance of each chronotype at the optimal time of day, we compared the morning performance of subjects classified with high morningness and the afternoon scores of subjects with high eveningness [instead of night performance, as was the case in a previous study (Goldstein et al., 2007)]. ANCOVA with covariates age and sex were performed. In these ANCOVAs, dependent variables were scores on performance-type cognitive tests.

For analyses of personality measures, we performed ANCOVAs with sex and chronotype as fixed factors and age as a covariate.

\section{Statistical analyses of imaging data}

We investigated rGMD associated with individual differences in morningness-eveningness. Statistical analyses of morphological data were performed using VBM5 software, an extension of SPM5. In the whole-brain multiple regression analyses, we tested for a relationship between morningness-eveningness assessed by MEQ and rGMD. The analyses were performed with sex, age, RAPM score, and total intracranial volume (TIV; total GM volume + total WM volume + total CSF volume) as additional covariates, resulting in five covariates in total. Second, we investigated whether the relationships between $\mathrm{rGMD}$ and the MEQ score differed between sexes (whether the interaction between sex and the MEQ score affected rGMD). In the whole brain analysis, we used a voxel wise ANCOVA in which sex difference was a group factor (using the full factorial option of SPM5). In this analysis, age, RAPM score, the MEQ score and TIV were covariates. All of these covariates, except TIV, were modeled so that each covariate's unique relationship with rGMD could be seen in each sex (using 
the interactions option in SPM5), which would allow the interaction effects of sex and the covariates to be investigated. The TIV was modeled so that this covariate has a common relationship with rGMD across sexes. The interaction effect between sex and the MEQ score on rGMD were assessed using t-contrasts. Finally, for analyses of chronotype, we performed a voxel-wise ANCOVA in which the morningness-eveningness chronotype was a group factor (using the full factorial option of SPM5) and age, sex, and TIV were covariates. All covariates were modeled so that these covariates have common relationships with rGMD across different chronotypes. The main effect of chronotype on rGMD was assessed using F-contrasts.

For further details of statistical models, please see Supplemental Methods. For t-contrast, the statistical significance level was set at $P<0.05$, corrected at the non-isotropic adjusted cluster level (family-wise-error) (Hayasaka et al., 2004) with an underlying voxel level of $P<0.001$. For the reasons of using this test, see Supplemental Methods. However, for assessing the association with rGMD in hypothalamic areas around the suprachiasmatic nucleus, rGMD images smoothed with a 3-mm FWHM. We applied the small volume correction around a 3-mm radius sphere surrounding the bilateral voxels of MNI coordinates $(\mathrm{x}, \mathrm{y}, \mathrm{z}) \pm 1.5,0,-15$, which are closest to the nucleus (Baroncini et al., 2012). Since it was difficult to measure the SCN with the spatial resolution achieved, we investigated the significance for the hypothalamic area around the suprachiasmatic nucleus. In these areas, the statistical threshold was set at $P<0.05$, corrected for the false discovery rate (FDR).

For analyses of F-contrasts, which cannot use the cluster size test described above, we applied a statistical threshold of $P<0.05$ corrected for FDR. 


\section{Results}

Relationships between MEQ scores (chronotype) and psychometric test scores as assessed by multiple regression

Table 1 shows the average and standard deviation (SD) of age and RAPM and MEQ scores in males and females. Fig. 1 shows the distributions of MEQ scores and category types in males and females. Multiple regression analysis corrected for the effect of age showed that females had significantly higher MEQ scores (or morningness) than males. Greater morningness in females is consistent with many (Adan and Natale, 2002; Randler, 2007) but not all of previous studies (Paine et al., 2006), A recent study (Duarte et al., 2014) found greater morningness only in younger females, while older females had lower morningness than older males. Because the mean age of our female subjects was $\sim 21$ year, the current results are generally consistent with this recent finding (Duarte et al., 2014). After correcting for the effect of sex, age was not significantly correlated with the MEQ score, which probably reflects the small age range in the present study.

After correcting for age and sex, the MEQ score was significantly and negatively correlated with scores for the measures of psychometric intelligence (Raven's advanced progressive matrix and Tanaka B-type intelligence test), visual and verbal working memory tests, novelty seeking, and harm avoidance, and was positively correlated with scores for persistence, self-directedness, cooperativeness, and self-transcendence. The MEQ score was not significantly correlated with reward dependence or the score for S-A creativity test. Table 2 presents the statistical values of these associations. The strength of the association (standardized partial regression coefficient $(\beta))$ between cognitive functions and morningness-eveningness did not 
differ substantially, even when the analyses were performed only with data obtained in the morning (Table 2). Thus, subsequently, we analyzed all data without considering when the test was performed.

Associations between morningness and lower psychometric intelligence, lower working memory performance, lower novelty seeking, lower harm avoidance, higher persistence, higher self-directedness, and higher cooperativeness were observed in previous studies (Lee et al., 2012; Randler and Saliger, 2011; Roberts and Kyllonen, 1999), although in a study with fewer subjects, some associations did not reach significance. Unlike in a previous study that showed an association between creativity measured by a visual divergent thinking test (Giampietro and Cavallera, 2007) and eveningness, in the present study, eveningness was not associated with higher creativity as measured by a verbal divergent thinking test.

Association of chronotype with psychometric scores as assessed by ANCOVA

For adjusted evaluation of the relationships between performance-type cognitive test scores and chronotypes, ANCOVAs including age, sex, chronotype, time of the test, and the interaction between chronotype and test time were employed. Results revealed no significant effects of chronotype, test time, or their interaction on any of the cognitive test scores except the creativity test. In this latter case, ANCOVA of the S-A creativity test revealed a significant main effect of chronotype and time of test as well as a significant chronotype $\times$ test time interaction. Post hoc t-tests between different groups revealed that the psychometric test scores of morningness subjects at night were significantly better than scores in the afternoon and morning, and also better than those of eveningness and intermediate subjects at night. Thus, this interaction appeared to be 
driven by the higher scores of morningness subjects at night. However, though the statistical values are strong, fewer than 10 subjects of morningness type went through tests at night and this MRI correlation study design was not optimized for investigating the effects of chronotype on cognitive test performance. Thus, future studies are required to confirm these findings, particularly the novel result of a significant association between chronotype and creativity test scores. Averages scores of each chronotype at each testing time are presented with statistical values in Table 3.

The lack of significance in other tests may reflect a lack of sensitivity due to the group divisions (i.e., comparisons among 3 groups) because a large proportion of the total variance was lost by grouping since most subjects fell into the intermediate type category. However, ANCOVAs including the same covariates after removal of the intermediate group revealed significant group differences in verbal WM and creativity test scores, as well as a trend for a group difference in Raven's advanced progressive matrix test score.

To compare the performance of each chronotype at the optimal time of day, we compared morningness group test performance in the morning and eveningness group test performance in the afternoon time [instead of at night time as was the case in the previous studies (Goldstein et al., 2007)]. ANCOVA with covariates age and sex revealed significantly better performance of eveningness group subjects in the afternoon compared to morningness subjects in the morning on the TBIT $(P=0.004, \mathrm{~F}=8.645)$, visual working memory test $(P=0.003, \mathrm{~F}=9.043)$, and verbal working memory test $(P$ $=0.001, \mathrm{~F}=12.309)$. There were no other significant results. However, it should be noted that in these tests of significant results, both eveningness and morningness subjects had higher average scores in the afternoon than the morning. 
To assess the relationship between chronotype and personality measures, ANCOVAs involving age, sex, and chronotype as covariates were employed. Results revealed significant effects of chronotype on all personality measures. Significant group differences were generally congruent with results of multiple regression analyses (See Table 4 all results and statistical values). However, in the case of reward dependence, there was a significant effect of chronotype despite the lack of a significant result in multiple regression analysis. In ANCOVA of reward dependence, the only significant group difference was the greater reward dependence in the intermediate group in comparison with the morningness group.

\section{Correlation between rGMD and morningness-eveningness}

We investigated the association between rGMD and individual differences in morningness-eveningness. Multiple regression analysis including age, sex, RAPM score, and total brain volume revealed that the MEQ score was significantly and positively correlated with rGMD in the areas of the bilateral lateral orbitofrontal cortex (Figs. 2, 3a). The same analysis revealed that the MEQ score was significantly and negatively correlated with rGMD in an anatomical cluster that spread mostly in the precuneus, as well as in an anatomical cluster that spread mostly in the left PPC (Figs. 2, 3a). No other significant findings were observed. Table 5 presents the statistical values of these results.

When the RAPM score was removed from the analyses, the significance and insignificance of these results did not change. Table 5 presents the statistical values of these results. 
Effects of interaction between sex and morningness-eveneningness on rGMD

Analysis of covariance using data regarding age, sex, and RAPM and TIV scores from both sexes revealed that interaction between the MEQ score and sex had no effects on rGMD. The insignificance of these results did not change when the RAPM score was removed from the model of analysis of covariance.

Association of rGMD with morningness-eveningness chronotype assess by ANCOVA

ANCOVA using age, sex, chronotype (instead of MEQ score), and TIV for both sexes revealed no significant effects of chronotype on rGMD. Again, the lack of significance may reflect the lack of sensitivity due to the group divisions (comparisons among 3 groups), particularly the loss total variance due to the great proportion of subjects in the intermediate type.

Associations between rGMD and morningness-eveningness in the bilateral suprachiasmatic nuclei using images with low smoothness

We investigated the association between rGMD and chronotype separately for the hypothalamic clusters because of the small size of bilateral suprachiasmatic nuclei required analysis of images with low smoothness (3-mm FWHM). Regions of interest analyses using multiple regression with the same covariates in these hypothalamic clusters revealed a significant positive correlation between MEQ and RGMD in both the left cluster $(P<0.05$, corrected for FDR, 25 voxels, $\mathrm{t}=2.58$, peak coordinate $\mathrm{x}, \mathrm{y}, \mathrm{z}=0$, $1.5,-15)$ and the right cluster $(\mathrm{P}<0.05$, corrected for FDR, 26 voxels, $\mathrm{t}=2.58$, peak coordinate $\mathrm{x}, \mathrm{y}, \mathrm{z}=1.5,1.5,-15)$. In addition, $\mathrm{rGMD}$ of the two bilateral coordinates $(\mathrm{x}$, $\mathrm{y}, \mathrm{z}= \pm 1.5,0,-15)$ closest to the bilateral suprachiasmatic nuclei showed a significant 
positive correlation with MEQ (left: $P=0.007$, uncorrected, $t=2.44$; right: $P=0.009$, uncorrected, $t=2.39$; Fig. 5). However, considering the voxel size of the raw image (1 $\mathrm{mm}$ ) relative to the size of the nucleus, co-development of other regions of the hypothalamus may contribute to this relationship. Interaction between the MEQ score and sex had no effects on rGMD in these voxels.

\section{Discussion}

To the best of our knowledge, this is the first study to investigate associations between brain structures and morningness-eveningness. Consistent with some of our hypotheses, we demonstrated that morningness (less eveningness) was associated with (a) lower rGMD in the precuneus and adjacent areas, (b) lower rGMD in the left PPC and adjacent areas, and (c) higher rGMD in the bilateral OFC. Further, our exploratory analyses revealed that (d) higher rGMD in bilateral hypothalamic clusters around the suprachiasmatic nuclei was associated with morningness. Taken together with the findings of further post-hoc analyses, the present findings suggest that these structural characteristics are linked to the associations between morningness and (A) lower cognitive functions, (B) higher competence in pro-social and self-disciplinary cognitive components, (C) less attentional and emotional problems, and (D) increased functional integrity of the bilateral hypothalamic clusters around the suprachiasmatic nuclei, as discussed below.

We associated lower rGM in the precuneus and OFC with better functioning of these regions for the following reasons as was the case with previous studies by ourselves and others, and as discussed in our previous studies (for details, see Kanai et al., 2011; Takeuchi et al., 2011g, 2013a; Takeuchi et al., 2014b). First, in these areas, 
increased competence in cognitions that are functionally associated with these areas is also associated with decreases in rGM structures (or increased cortical thinning) in young adults (for details, see Takeuchi et al., 2011g, 2013a; Takeuchi et al., 2014b). In these regions, developmental cortical thinning, which is probably caused by synaptic pruning (Sowell et al., 2003), is observed after adolescence, and advanced development of neural systems, which may well be related to matured cognitive abilities in most cases, is characterized by advanced cortical thinning and reduced rGM. A summary of the association between decreased rGM and increased functioning in these areas can be found in our previous study (Takeuchi et al., 2011g). Although the association between reduced rGM and better cognitive function is not congruent with some clinical findings that show deteriorated cognitive functioning with reduced rGM, these mechanisms may well be caused by different physiological mechanisms such as neuronal degeneration, including neuron loss. These could lead to deficits of competencies and reduced GM signaling in VBM (Takeuchi et al., 2011g).

Lower rGMD in OFC of subjects with higher eveningness may be comparable to the results of previous studies that linked this structure and other parts of the anterior brain areas to psychometric intelligence and working memory, and may suggest that this structure contributes to the associations between eveningness and these cognitive components. The lateral parts of OFC have not typically been associated with these higher order cognitive functions in functional imaging studies (Takeuchi et al., 2012a). However, structurally, a wide range of prefrontal and anterior cingulate areas have been linked to psychometric intelligence and working memory (Frangou et al., 2004; Gong et al., 2005; Haier et al., 2004; Luerding et al., 2008; Shaw et al., 2006), perhaps suggesting that GM structures in adjacent areas tend to co-develop irrespective of the 
functions and networks the areas belong to (Zielinski et al., 2010). In particular, GM structures in the lateral OFC have been linked to psychometric intelligence and working memory, although the positivity or negativity of the association between these functions and the amount of GM seems to differ among different samples (Frangou et al., 2004; Luerding et al., 2008; Shaw et al., 2006). On the other hand, as described in the Introduction and as shown in the present study, these cognitive functions have been robustly associated with eveningness. Thus, the reduced amount of GM in these areas in subjects with higher eveningness may reflect their higher competence with respect to these cognitive functions. Consistent with this notion, our post hoc analyses revealed a significant negative correlation or at least a negative trend between cluster rGMD and both verbal and visual working memory performance and the Tanaka B-type intelligence test score (for details, see Supplemental Methods and Results). An alternative speculative explanation is that reduced GM in these areas may be a consequence of lifestyle factors related to the morningness-eveningness chronotype. It has been shown that extensive cognitive demand leads to reduced prefrontal GM (Takeuchi et al., 2011c; Takeuchi et al., 2011d). Thus, for example, the activities associated with being a university student may both lead to increased eveningness and reduced GM. However, future longitudinal studies are required to test these speculations.

Lower rGMD in the precuneus of subjects with higher morningness may be comparable to the results of previous studies that linked this structure to pro-social and self-disciplinary cognitive components, and may suggest that this structure contributes to the associations between morningness and these cognitive components. The precuneus has many functions, but functional imaging studies have consistently shown 
that one of these functions involves cognitive processing related to one's own mind and that of others (e.g., first person perspective taking and third perspective taking)(Vogeley et al., 2004). Structurally, the GM structure in this area has been linked to pro-social (e.g., empathetic competence and agreeableness) and self-disciplinary cognitive (e.g., intrapersonal emotional intelligence, less novelty seeking, persistence, and self-directedness) components (Gardini et al., 2009); particularly in young adults, the reduced amount of GM in this region has been associated with higher self-disciplinary and pro-social cognitive components (Banissy et al., 2012; Coutinho et al., 2013; Takeuchi et al., 2011g; Takeuchi et al., 2014a; Takeuchi et al., 2014b). On the other hand, as described in the Introduction, morningness has been robustly associated with self-disciplinary (e.g., less novelty seeking, persistence, self-directedness, and conscientiousness) and pro-social cognitive components (e.g., agreeableness and cooperativeness) (Lee et al., 2012; Randler, 2008; Randler and Saliger, 2011). Thus, the reduced amount of GM in these areas in subjects with higher morningness may reflect their higher competence in pro-social and self-disciplinary cognitive components. Partly congruent with these notions, the mean rGMD in this cluster negatively correlated with self-directedness and sympathy and positively correlated with novelty seeking, which is linked to impulsiveness, a trait low in subjects with morningness (Cloninger et al., 1993) (for details, see Supplemental Methods and Results).

Higher rGMD in the left PPC and adjacent occipital areas of subjects with higher eveningness may be comparable to the results of previous studies that robustly linked this structure to attentional measures, and may suggest that this structure contributes to the associations between eveningness and attentional problems in everyday life. The left PPC may have many functions, but one of them is a key role in 
top-down and bottom-up attention (Ciaramelli et al., 2010). Recent structural studies associated the increased amount of GM in this area with distractibility in everyday life (Kanai et al., 2011) as well as with less stability in binocular rivalry (Kanai et al., 2010). Subjects with attention deficit show less stability in binocular rivalry (Gorenstein et al., 1989). Critically, these studies demonstrated that transcranial magnetic stimulation of this area affects the related measures, suggesting causal relationships between structures in this area and attentional characteristics. On the other hand, as described in the Introduction, eveningness has been robustly associated with attentional problems in everyday life as well as with attention deficit disorder despite superior cognitive performance (Caci et al., 2009; Gau et al., 2007; Susman et al., 2007). Thus, the increased amount of GM in these areas in subjects with higher eveningness may reflect more attentional problems in their everyday lives. Finally, partly congruent with these notions, post-hoc analyses revealed that rGMD in this cluster showed a tendency toward a positive correlation with concentration problems in daily life (for details, see

\section{Supplemental Methods and Results).}

Inconsistent with our hypothesis, brain structures typically linked to negative emotion were not significantly correlated with morningness-eveningness. However, interestingly, our subsequent analyses revealed that psychological variables rather strongly linked to negative emotion and the structures in this area may be common neural correlates of eveningness, negative emotion, and attentional problems, which are all associated with one another, as described below. Our further analyses also revealed that harm avoidance, which was associated with negative emotion (Sen et al., 2004) as

well as eveningness (Adan et al., 2010), and suicide ideation were also positively correlated with rGMD in the left PPC (for details, see Supplemental Methods and 
Supplemental Results). An association between harm avoidance and rGMD in this area has been reported previously (Gardini et al., 2009). Interestingly, attentional problems in everyday life have been consistently and strongly associated with negative emotion (Broadbent et al., 1982). Taken together, although the mechanisms of causation remain unclear, it appears that the structures in this area may be common neural correlates of eveningness, negative emotion, and attentional problems, which are all associated with one another. Considering the association between this structure and traits linked to negative emotions, one possibility is that certain aspects of attention (such as a focus on negative ideas) may cause distractibility in everyday life (Joormann et al., 2006; Lyubomirsky et al., 2003). Another possibility is that increased rGMV in the PPC may be a consequence of lifestyle factors associated with eveningness. For example, increased videogame play is known to lead to more eveningness (Krejci et al., 2011) and excessive videogame play is associated with both negative mood (Krejci et al., 2011; Mehroof and Griffiths, 2010) and attention problems (Swing et al., 2010). Finally, videogame play is known to lead to increased rGMV in the PPC (Kühn and Gallinat, 2014). Thus, these rGMD changes in the PPC may underlie the observed associations among morningness-eveningness, attention problems, and negative emotions. However, these speculations need to be confirmed in future studies.

The significant associations between rGMD and morningness observed in the bilateral hypothalamic clusters around the suprachiasmatic nuclei in our exploratory analysis may suggest that the reduced amount of GM in these areas may be associated with the reduced functioning of these areas. To the best of our knowledge, there is no evidence to suggest that unlike the areas in the cerebral cortex discussed above, low rGMD has to be associated with better functioning in this hypothalamic area. Thus, the 
higher rGMD in this area may suggest the functional integrity of this area. Consistent with this notion, lesions or dysfunctions of these nuclei typically lead to more nocturnal behaviors (Edgar et al., 1993) and delayed sleep phase disorder, which has typically been ascribed to lower or reduced functioning of the suprachiasmatic nuclei show eveningness (Crowley et al., 2007). Further, lesions or dysfunctions of these nuclei increase daytime sleep and overall sleep (Easton et al., 2004; Edgar et al., 1993). Consistent with this idea, rGMD of these areas showed significant negative correlations or at least negative trends with amount of sleep, the habit of taking a nap, and amount of sleep before the holidays (for details, see Supplemental Methods and Results). These findings are despite the finding of no correlation between the MEQ score and the habit of taking a nap and the small psychological correlation with the normal amount of sleep. No other psychological variables associated with morningness-eveningness in this study showed a significant or substantial correlation with rGMD in the left or right suprachiasmatic nuclei. However, these nuclei are too small to be detected by standard T1-weighted structural images (Turner and Schönknecht, 2012); therefore, the observed associations are better understood as consequence of co-development of multiple hypothalamic structures.

Another limitation is the complex nature of MEQ score and the morningness-eveningness construct. Sleep homeostasis and circadian functions influence schedule preference independently (Mongrain et al., 2006) but interact to regulate sleep-wake cycles (Dijk and von Schantz, 2005). However, they have distinct biological bases (Viola et al., 2007). Also as discussed above, other daily habits such as late-night study and videogame play are likely to lead to eveningness (Krejci et al., 2011); however, such factors were not accounted for in this study. Future studies using 
more advanced cofactor analyses are needed to investigate these issues. For other limitations, see Supplemental Discussion.

In conclusion, we revealed how morningness-eveningness and other associated psychological variables are correlated with rGMD in certain regions. However, we could not reveal why morningness is associated with specific psychological variables. This matter should be studied further in future using alternative methodologies.

\section{Acknowledgments}

We thank Yuki Yamada for operating the MRI scanner, Haruka Nouchi for conducting the psychological tests, all other assistants for helping with the experiments and the study, and the study participants and all our other colleagues at IDAC, Tohoku University for their support. This study was supported by JST/RISTEX, JST/CREST, a Grant-in-Aid for Young Scientists (B) (KAKENHI 23700306), and a Grant-in-Aid for Young Scientists (A) (KAKENHI 25700012) from the Ministry of Education, Culture, Sports, Science, and Technology.

\section{References}

Adan A, Natale V (2002) Gender differences in morningness-eveningness preference. Chronobiol Int 19:709-720.

Adan A, Lachica J, Caci H, Natale V (2010) Circadian typology and temperament and character personality dimensions. Chronobiol Int 27:181-193.

Akashiba T, Kawahara S, Akahoshi T, Omori C, Saito O, Majima T, Horie T (2002) Relationship between quality of life and mood or depression in patients with severe obstructive sleep apnea syndrome. CHEST Journal 122:861-865. 
Aratake Y, Tanaka K, Wada K, Watanabe M, Katoh N, Sakata Y, Aizawa Y (2007) Development of Japanese version of the checklist individual strength questionnaire in a working population. J Occup Health 49:453-460.

Ashburner J, Friston KJ (2000) Voxel-based morphometry-the methods. Neuroimage 11:805-821.

Baehr EK, Revelle W, Eastman CI (2000) Individual differences in the phase and amplitude of the human circadian temperature rhythm: with an emphasis on morningness-eveningness. J Sleep Res 9:117-127.

Baird A, Coogan A, Siddiqui A, Donev R, Thome J (2012) Adult attention-deficit hyperactivity disorder is associated with alterations in circadian rhythms at the behavioural, endocrine and molecular levels. Mol Psychiatry 17:988-995.

Banissy MJ, Kanai R, Walsh V, Rees G (2012) Inter-individual differences in empathy are reflected in human brain structure. Neuroimage 62:2034-2039.

Baroncini M, Jissendi P, Balland E, Besson P, Pruvo J-P, Francke J-P, Dewailly D, Blond S, Prevot V (2012) MRI atlas of the human hypothalamus. Neuroimage 59:168-180.

Broadbent DE, Cooper PF, FitzGerald P, Parkes KR (1982) The cognitive failures questionnaire (CFQ) and its correlates. British Journal of Clinical Psychology 21:1-16.

Caci H, Bouchez J, Baylé FJ (2009) Inattentive symptoms of ADHD are related to evening orientation. J Atten Disord 13:36-41.

Ciaramelli E, Grady C, Levine B, Ween J, Moscovitch M (2010) Top-down and bottom-up attention to memory are dissociated in posterior parietal cortex: neuroimaging and neuropsychological evidence. The Journal of Neuroscience 
$30: 4943-4956$.

Cloninger CR, Svrakic DM, Przybeck TR (1993) A psychobiological model of temperament and character. Arch Gen Psychiatry 50:975-990.

Coutinho JF, Sampaio A, Ferreira M, Soares JM, Gonçalves OF (2013) Brain correlates of pro-social personality traits: a voxel-based morphometry study. Brain Imaging Behav:1-7.

Crowley SJ, Acebo C, Carskadon MA (2007) Sleep, circadian rhythms, and delayed phase in adolescence. Sleep medicine 8:602-612.

Díaz-Morales JF, Escribano C (2013) Predicting school achievement: The role of inductive reasoning, sleep length and morningness-eveningness. Personality and Individual differences 55:106-111.

Díaz-Morales JF, Ferrari JR, Cohen JR (2008) Indecision and avoidant procrastination: The role of morningness - eveningness and time perspective in chronic delay lifestyles. The journal of general psychology 135:228-240.

Darlington TK, Wager-Smith K, Ceriani MF, Staknis D, Gekakis N, Steeves TD, Weitz CJ, Takahashi JS, Kay SA (1998) Closing the circadian loop: CLOCK-induced transcription of its own inhibitors per and tim. Science 280:1599-1603.

Dijk D-J, von Schantz M (2005) Timing and consolidation of human sleep, wakefulness, and performance by a symphony of oscillators. J Biol Rhythms 20:279-290.

Duarte L, Menna-Barreto L, Miguel M, Louzada F, Araújo J, Alam M, Areas R, Pedrazzoli M (2014) Chronotype ontogeny related to gender. Braz J Med Biol Res 47:316-320.

Duffy JF, Rimmer DW, Czeisler CA (2001) Association of intrinsic circadian period with morningness-eveningness, usual wake time, and circadian phase. Behav 
Neurosci 115:895-899.

Easton A, Meerlo P, Bergmann B, Turek F (2004) The suprachiasmatic nucleus regulates sleep timing and amount in mice. Sleep 27:1307-1318.

Edgar DM, Dement WC, Fuller CA (1993) Effect of SCN lesions on sleep in squirrel monkeys: evidence for opponent processes in sleep-wake regulation. The Journal of Neuroscience 13:1065-1079.

Frangou S, Chitins X, Williams SCR (2004) Mapping IQ and gray matter density in healthy young people. Neuroimage 23:800-805.

Gardini S, Cloninger CR, Venneri A (2009) Individual differences in personality traits reflect structural variance in specific brain regions. Brain Research Bulletin 79:265-270.

Gau SS-F, Shang C-Y, Merikangas KR, Chiu Y-N, Soong W-T, Cheng AT-A (2007) Association between morningness-eveningness and behavioral/emotional problems among adolescents. J Biol Rhythms 22:268-274.

Giampietro M, Cavallera G (2007) Morning and evening types and creative thinking. Personality and Individual differences 42:453-463.

Goldstein D, Hahn CS, Hasher L, Wiprzycka UJ, Zelazo PD (2007) Time of day, intellectual performance, and behavioral problems in Morning versus Evening type adolescents: Is there a synchrony effect? Personality and Individual Differences 42:431-440.

Gong QY, Sluming V, Mayes A, Keller S, Barrick T, Cezayirli E, Roberts N (2005) Voxel-based morphometry and stereology provide convergent evidence of the importance of medial prefrontal cortex for fluid intelligence in healthy adults. Neuroimage 25:1175-1186. 
Good CD, Johnsrude IS, Ashburner J, Henson RNA, Friston KJ, Frackowiak RSJ (2001) A Voxel-Based Morphometric Study of Ageing in 465 Normal Adult Human Brains. Neuroimage 14:21-36.

Gorenstein EE, Mammato CA, Sandy JM (1989) Performance of inattentive-overactive children on selected measures of prefrontal-type function. J Clin Psychol 45:619-632.

Haier RJ, Jung RE, Yeo RA, Head K, Alkire MT (2004) Structural brain variation and general intelligence. Neuroimage 23:425-433.

Hayasaka S, Phan KL, Liberzon I, Worsley KJ, Nichols TE (2004) Nonstationary cluster-size inference with random field and permutation methods. Neuroimage 22:676-687.

Horne JA, Ostberg O (1976) A self-assessment questionnaire to determine morningness-eveningness in human circadian rhythms. Int $\mathrm{J}$ Chronobiol 4:97-110.

Hu X, Erb M, Ackermann H, Martin JA, Grodd W, Reiterer SM (2011) Voxel-based morphometry studies of personality: Issue of statistical model specification—effect of nuisance covariates. Neuroimage 54:1994-2005.

Hur Y-M, Lykken DT (1998) Genetic and environmental influence on morningnesseveningness. Personality and individual differences 25:917-925.

Iidaka T, Matsumoto A, Ozaki N, Suzuki T, Iwata N, Yamamoto Y, Okada T, Sadato N (2006) Volume of left amygdala subregion predicted temperamental trait of harm avoidance in female young subjects. A voxel-based morphometry study. Brain Research 1125:85-93.

Inouye TS-i, Kawamura H (1982) Characteristics of a circadian pacemaker in the 
suprachiasmatic nucleus. Journal of comparative physiology 146:153-160.

Ishihara K, Miyashita A, Inugami M, Fukuda K, Yamazaki K, Miyata Y (1986) Nihongoban-asagata-yorugata(Morningness-Eveningness)

shitsumonshiniyoru-chosakekka (The results of investigation by the Japanese version of Morningess-Eveningness questionnaire.). Shinrigakukenkyu (The Japanese journal of psychology) 57:87-91.

Iwata N, Uno B, Suzuki T (1994) Psychometric Properties of the 30 - item Version General Health Questionnaire in Japanese. Psychiatry Clin Neurosci 48:547-556.

Jin X, Shearman LP, Weaver DR, Zylka MJ, De Vries GJ, Reppert SM (1999) A molecular mechanism regulating rhythmic output from the suprachiasmatic circadian clock. Cell 96:57-68.

Joormann J, Dkane M, Gotlib IH (2006) Adaptive and maladaptive components of rumination? Diagnostic specificity and relation to depressive biases. Behav Ther $37: 269-280$.

Kühn S, Gallinat J (2014) Amount of lifetime video gaming is positively associated with entorhinal, hippocampal and occipital volume. Mol Psychiatry 19:842-847.

Kanai R, Bahrami B, Rees G (2010) Human parietal cortex structure predicts individual differences in perceptual rivalry. Curr Biol 20:1626-1630.

Kanai R, Dong MY, Bahrami B, Rees G (2011) Distractibility in daily life is reflected in the structure and function of human parietal cortex. The Journal of neuroscience 31:6620-6626.

Katzenberg D, Young T, Finn L, Lin L, King D, Takahashi J, Mignot E (1998) A CLOCK polymorphism associated with human diurnal preference. Sleep 
21:569-576.

Kijima N, Saito R, Takeuchi M, Yoshino A, Ono Y, Kato M, Kitamura T (1996) Cloninger-no-kishitsu-to-seikaku-no-7inshimodel-oyobi-nihongoban [Cloninger's seven-factor model of temperament and character and Japanese version of Temperament and Character Inventory (TCI)]. Seishinka-shindangaku [Archives of Psychiatric Diagnosis and Clinical Evaluation] 7:379-399.

Killgore W, Killgore D (2007) Morningness-eveningness correlates with verbal ability in women but not men. Perceptual and Motor Skills 104:335-338.

Klein A, Andersson J, Ardekani BA, Ashburner J, Avants B, Chiang M-C, Christensen GE, Collins DL, Gee J, Hellier P (2009) Evaluation of 14 nonlinear deformation algorithms applied to human brain MRI registration. Neuroimage 46:786-802.

Krejci M, Wada K, Nakade M, Takeuchi H, Noji T, Harada T (2011) Effects of video game playing on the circadian typology and mental health of young Czech and Japanese children. Psychology 2:674-680.

Lee S, Park JE, Cho SJ, Cho IH, Lee YJ, Kim SJ (2012) Association between morningness - eveningness and temperament and character in community-dwelling Korean adults. Asia-Pacific Psychiatry Article first published online.

Luerding R, Weigand T, Bogdahn U, Schmidt-Wilcke T (2008) Working memory performance is correlated with local brain morphology in the medial frontal and anterior cingulate cortex in fibromyalgia patients: structural correlates of pain-cognition interaction. Brain:3222-3231.

Lyubomirsky S, Kasri F, Zehm K (2003) Dysphoric rumination impairs concentration on academic tasks. Cognitive Therapy and Research 27:309-330. 
May A, Gaser C (2006) Magnetic resonance-based morphometry: a window into structural plasticity of the brain. Curr Opin Neurol 19:407-411.

Mehroof M, Griffiths MD (2010) Online gaming addiction: the role of sensation seeking, self-control, neuroticism, aggression, state anxiety, and trait anxiety. Cyberpsychology, behavior, and social networking 13:313-316.

Mongrain V, Carrier J, Dumont M (2006) Circadian and homeostatic sleep regulation in morningness-eveningness. J Sleep Res 15:162-166.

Ochsner K, Knierim K, Ludlow D, Hanelin J, Ramachandran T, Glover G, Mackey S (2004) Reflecting upon feelings: an fMRI study of neural systems supporting the attribution of emotion to self and other. Cognitive Neuroscience, Journal of $16: 1746-1772$.

Oldfield RC (1971) The assessment and analysis of handedness: the Edinburgh inventory. Neuropsychologia 9:97-113.

Paine S-J, Gander PH, Travier N (2006) The epidemiology of morningness/eveningness: influence of age, gender, ethnicity, and socioeconomic factors in adults (30-49 years). J Biol Rhythms 21:68-76.

Peelle JE, Cusack R, Henson RN (2012) Adjusting for global effects in voxel-based morphometry: gray matter decline in normal aging. Neuroimage 60:1503-1516.

Piffer D, Ponzi D, Sapienza P, Zingales L, Maestripieri D (2014) Morningnesseveningness and intelligence among high-achieving US students: Night owls have higher GMAT scores than early morning types in a top-ranked MBA program. Intelligence 47:107-112.

Randler C (2007) Gender differences in morningness-eveningness assessed by self-report questionnaires: A meta-analysis. Personality and Individual 
Differences 43:1667-1675.

Randler C (2008) Morningness-eveningness, sleep-wake variables and big five personality factors. Personality and Individual differences 45:191-196.

Randler C, Frech D (2006) Correlation between morningness-eveningness and final school leaving exams. Biol Rhythm Res 37:233-239.

Randler C, Saliger L (2011) Relationship between morningness-eveningness and temperament and character dimensions in adolescents. Personality and Individual differences 50:148-152.

Raven J (1998) Manual for Raven's progressive matrices and vocabulary scales. Oxford: Oxford Psychologists Press.

Roberts RD, Kyllonen PC (1999) Morningness-eveningness and intelligence: early to bed, early to rise will likely make you anything but wise! Personality and Individual differences 27:1123-1133.

Schmidt C, Collette F, Leclercq Y, Sterpenich V, Vandewalle G, Berthomier P, Berthomier C, Phillips C, Tinguely G, Darsaud A (2009) Homeostatic sleep pressure and responses to sustained attention in the suprachiasmatic area. Science 324:516-519.

Selvi Y, Aydin A, Atli A, Boysan M, Selvi F, Besiroglu L (2011) Chronotype differences in suicidal behavior and impulsivity among suicide attempters. Chronobiol Int $28: 170-175$.

Sen S, Burmeister M, Ghosh D (2004) Meta-analysis of the association between a serotonin transporter promoter polymorphism (5-HTTLPR) and anxiety-related personality traits. American Journal of Medical Genetics Part B: Neuropsychiatric Genetics 127:85-89. 
Shaw P, Greenstein D, Lerch J, Clasen L, Lenroot R, Gogtay N, Evans A, Rapoport J, Giedd J (2006) Intellectual ability and cortical development in children and adolescents. Nature 440:676-679.

Smith CS, Reilly C, Midkiff K (1989) Evaluation of three circadian rhythm questionnaires with suggestions for an improved measure of morningness. J Appl Psychol 74:728-738.

Sowell ER, Peterson BS, Thompson PM, Welcome SE, Henkenius AL, Toga AW (2003) Mapping cortical change across the human life span. Nature Neuroscience 6:309-315.

Strayer J, Roberts W (2004) Empathy and Observed Anger and Aggression in Five-Year-Olds. Soc Dev 13:1-13.

Susman EJ, Dockray S, Schiefelbein VL, Herwehe S, Heaton JA, Dorn LD (2007) Morningness/eveningness, morning-to-afternoon cortisol ratio, and antisocial behavior problems during puberty. Dev Psychol 43:811.

Swing EL, Gentile DA, Anderson CA, Walsh DA (2010) Television and video game exposure and the development of attention problems. Pediatrics 126:214-221.

Taillard J, Philip P, Bioulac B (1999) Morningness/eveningness and the need for sleep. J Sleep Res 8:291-295.

Taillard J, Philip P, Coste O, Sagaspe P, Bioulac B (2003) The circadian and homeostatic modulation of sleep pressure during wakefulness differs between morning and evening chronotypes. J Sleep Res 12:275-282.

Takahashi JS, Hong H-K, Ko CH, McDearmon EL (2008) The genetics of mammalian circadian order and disorder: implications for physiology and disease. Nature Reviews Genetics 9:764-775. 
Takeuchi H, Taki Y, Sassa Y, Hashizume H, Sekiguchi A, Fukushima A, Kawashima R (2010a) Regional gray matter density associated with emotional intelligence: evidence from voxel-based morphometry. Human Brain Mapping:Epub ahead of print.

Takeuchi H, Taki Y, Sassa Y, Hashizume H, Sekiguchi A, Fukushima A, Kawashima R (2010b) Regional gray matter volume of dopaminergic system associate with creativity: Evidence from voxel-based morphometry Neuroimage 51:578-585.

Takeuchi H, Taki Y, Sassa Y, Hashizume H, Sekiguchi A, Fukushima A, Kawashima R (2010c) White matter structures associated with creativity: Evidence from diffusion tensor imaging. Neuroimage 51:11-18.

Takeuchi H, Taki Y, Hashizume H, Sassa Y, Nagase T, Nouchi R, Kawashima R (2011a) Failing to deactivate: the association between brain activity during a working memory task and creativity. Neuroimage 55:681-687.

Takeuchi H, Taki Y, Hashizume H, Sassa Y, Nagase T, Nouchi R, Kawashima R (2011b) Cerebral blood flow during rest associates with general intelligence and creativity. PLoS ONE 6:e25532.

Takeuchi H, Taki Y, Sassa Y, Hashizume H, Sekiguchi A, Fukushima A, Kawashima R (2011c) Working memory training using mental calculation impacts regional gray matter of the frontal and parietal regions. PLoS ONE 6:e23175.

Takeuchi H, Taki Y, Hashizume H, Sassa Y, Nagase T, Nouchi R, Kawashima R (2011d) Effects of training of processing speed on neural systems. J Neurosci $31: 12139-12148$.

Takeuchi H, Taki Y, Hashizume H, Sassa Y, Nagase T, Nouchi R, Kawashima R (2011e) Failing to deactivate: the association between brain activity during a working 
memory task and creativity. Neuroimage 55:681-687.

Takeuchi H, Taki Y, Sassa Y, Hashizume H, Sekiguchi A, Fukushima A, Kawashima R (2011f) Verbal working memory performance correlates with regional white matter structures in the fronto-parietal regions. Neuropsychologia 49:3466-3473

Takeuchi H, Taki Y, Sassa Y, Hashizume H, Sekiguchi A, Fukushima A, Kawashima R (2011g) Regional gray matter density associated with emotional intelligence: Evidence from voxel-based morphometry. Hum Brain Mapp 32:1497-1510.

Takeuchi H, Sugiura M, Sassa Y, Sekiguchi A, Yomogida Y, Taki Y, Kawashima R (2012a) Neural correlates of the difference between working memory speed and simple sensorimotor speed: an fMRI study. PLoS ONE 7:e30579.

Takeuchi H, Taki Y, Sassa Y, Hashizume H, Sekiguchi A, Fukushima A, Kawashima R (2013a) Brain structures associated with executive functions during everyday events in a non-clinical sample. Brain Struct Funct 218:1017-1032.

Takeuchi H, Taki Y, Sassa Y, Hashizume H, Sekiguchi A, Fukushima A, Kawashima R (2014a) Regional gray matter volume is associated with empathizing and systemizing in young adults. PLoS ONE 9:e84782.

Takeuchi H, Taki Y, Sassa Y, Hashizume H, Sekiguchi A, Nagase T, Nouchi R, Fukushima A, Kawashima R (2012b) Regional gray and white matter volume associated with Stroop interference: Evidence from voxel-based morphometry. Neuroimage 59:2899-2907.

Takeuchi H, Taki Y, Nouchi R, Sekiguchi A, Kotozaki Y, Miyauchi CM, Yokoyama R, Iizuka K, Hashizume H, Nakagawa S (2012c) A voxel-based morphometry study of gray and white matter correlates of a need for uniqueness. Neuroimage 63:1119-1126. 
Takeuchi H, Taki Y, Nouchi R, Hashizume H, Sekiguchi A, Kotozaki Y, Nakagawa S, Miyauchi CM, Sassa Y, Kawashima R (2013b) Effects of working memory-training on functional connectivity and cerebral blood flow during rest. Cortex 49:2106-2125.

Takeuchi H, Taki Y, Nouchi R, Hashizume H, Sekiguchi A, Kotozaki Y, Nakagawa S, Miyauchi CM, Sassa Y, Kawashima R (2013c) Anatomical correlates of self-handicapping tendency. Cortex 49:1148-1154.

Takeuchi H, Taki Y, Nouchi R, Sekiguchi A, Kotozaki Y, Miyauchi C, Yokoyama R, Iizuka K, Hashizume H, Nakagawa S (2014b) Regional gray matter density is associated with achievement motivation: evidence from voxel-based morphometry. Brain Struct Funct 219:71-83.

Taki Y, Hashizume H, Sassa Y, Takeuchi H, Asano M, Asano K, Kawashima R (2010) Breakfast Staple Types Affect Brain Gray Matter Volume and Cognitive Function in Healthy Children. PLoS ONE 5:e15213: 15211-15218.

Taki Y, Hashizume H, Sassa Y, Takeuchi H, Asano M, Asano K, Kotozaki Y, Nouchi R, Wu K, Fukuda H (2011) Correlation among body height, intelligence, and brain gray matter volume in healthy children. Neuroimage 59:1023-1027.

Testa C, Laakso MP, Sabattoli F, Rossi R, Beltramello A, Soininen H, Frisoni GB (2004) A comparison between the accuracy of voxel-based morphometry and hippocampal volumetry in Alzheimer's disease. J Magn Reson Imaging 19:274-282.

Turner R, Schönknecht P (2012) Structural studies of the hypothalamus and its nuclei in mood disorders. Psychiatry Research: Neuroimaging 201:1-9.

Viola AU, Archer SN, James LM, Groeger JA, Lo JC, Skene DJ, von Schantz M, Dijk 
D-J (2007) PER3 polymorphism predicts sleep structure and waking performance. Curr Biol 17:613-618.

Vogeley K, May M, Ritzl A, Falkai P, Zilles K, Fink GR (2004) Neural correlates of first-person perspective as one constituent of human self-consciousness. J Cogn Neurosci 16:817-827.

Yamasue H, Abe O, Suga M, Yamada H, Inoue H, Tochigi M, Rogers M, Aoki S, Kato N, Kasai K (2008) Gender-common and-specific neuroanatomical basis of human anxiety-related personality traits. Cereb Cortex 18:46-52.

Zielinski BA, Gennatas ED, Zhou J, Seeley WW (2010) Network-level structural covariance in the developing brain. Proc Natl Acad Sci U S A 107:18191-18196. 
Table 1

Demographic variables of the study participants

\begin{tabular}{lcclll}
\hline & \multicolumn{2}{c}{ Male } & & \multicolumn{2}{c}{ Female } \\
\cline { 2 - 3 } \cline { 5 - 6 } Measure & Mean & SD & & Mean & SD \\
& & & & \\
\hline Age & 20.80 & 1.97 & & 20.57 & 1.67 \\
RAPM & 28.92 & 3.75 & & 28.28 & 3.68 \\
MEQ & 48.84 & 7.82 & & 50.67 & 7.59 \\
\hline
\end{tabular}


Table 2 Statistical values for multiple regression analyses analyzing correlations between the MEQ score and other psychological variables

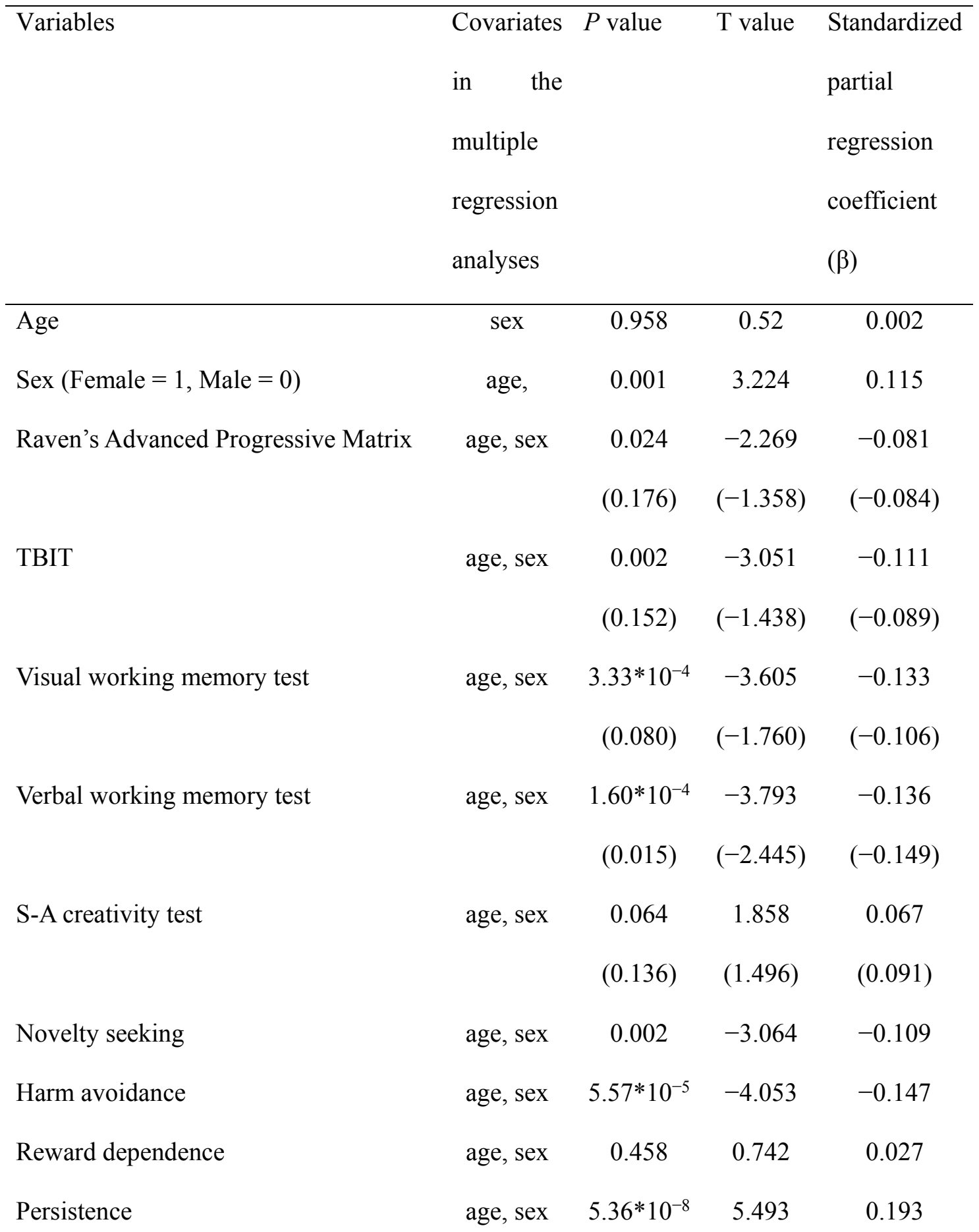




$\begin{array}{lcccc}\text { Self-directedness } & \text { age, sex } & 2.33 * 10^{-14} & 7.780 & 0.273 \\ \text { Cooperativeness } & \text { age, sex } & 5.20^{*} 10^{-10} & 6.294 & 0.225 \\ \text { Self-transcendence } & \text { age, sex } & 0.003 & 2.934 & 0.105\end{array}$

Data within brackets indicate analyses performed using only data obtained in the morning. 
Table 3 Performance of each chronotype at each timing of test and statistical values of the comparisons

\begin{tabular}{|c|c|c|c|c|c|c|c|}
\hline \multirow[t]{5}{*}{ Variables } & \multirow[t]{5}{*}{ Test time* } & Eveningness & Intermediate & Morningness & Main effect & Main effect & Interaction \\
\hline & & type & type & type & $(P, \mathrm{~F}$ value of & (P, F value of & effect $(P, \mathrm{~F}$ \\
\hline & & Time $1: \mathrm{N}=38$ & Time $1: \mathrm{N}=186$ & Time $1: \mathrm{N}=42$ & effects of & effects of test & value) \\
\hline & & Time $2: \mathrm{N}=56$ & Time $2: \mathrm{N}=270$ & Time $2: \mathrm{N}=49$ & chronotype) & time) & \\
\hline & & Time $3: \mathrm{N}=18$ & Time $3: \mathrm{N}=109$ & Time $3: \mathrm{N}=8$ & & & \\
\hline Raven's Advanced & Time 1 & $29.82 \pm 3.97$ & $28.22 \pm 4.32$ & $27.79 \pm 3.73$ & $0.200,1.611$ & $0.656,0.422$ & $0.638,0.634$ \\
\hline \multirow{2}{*}{ Progressive Matrix } & Time 2 & $29.07 \pm 4.19$ & $28.87 \pm 3.5$ & $27.96 \pm 3.49$ & & & \\
\hline & Time 3 & $28.33 \pm 3.83$ & $28.57 \pm 3.7$ & $27.75 \pm 3.7$ & & & \\
\hline \multirow[t]{3}{*}{ TBIT } & Time 1 & $112.05 \pm 10.18$ & $111.9 \pm 11.48$ & $106.07 \pm 13.22$ & $0.289,1.245$ & $0.061,2.812$ & $0.529,0.754$ \\
\hline & Time 2 & $114.21 \pm 13.69$ & $113.31 \pm 11.2$ & $110.44 \pm 11.51$ & & & \\
\hline & Time 3 & $113.44 \pm 11.3$ & $112.57 \pm 10.79$ & $112.88 \pm 9.43$ & & & \\
\hline Visual working & Time 1 & $28.47 \pm 3.24$ & $28.1 \pm 4.42$ & $27.05 \pm 3.67$ & $0.207,1.580$ & $0.101,2.296$ & $0.442,0.936$ \\
\hline
\end{tabular}




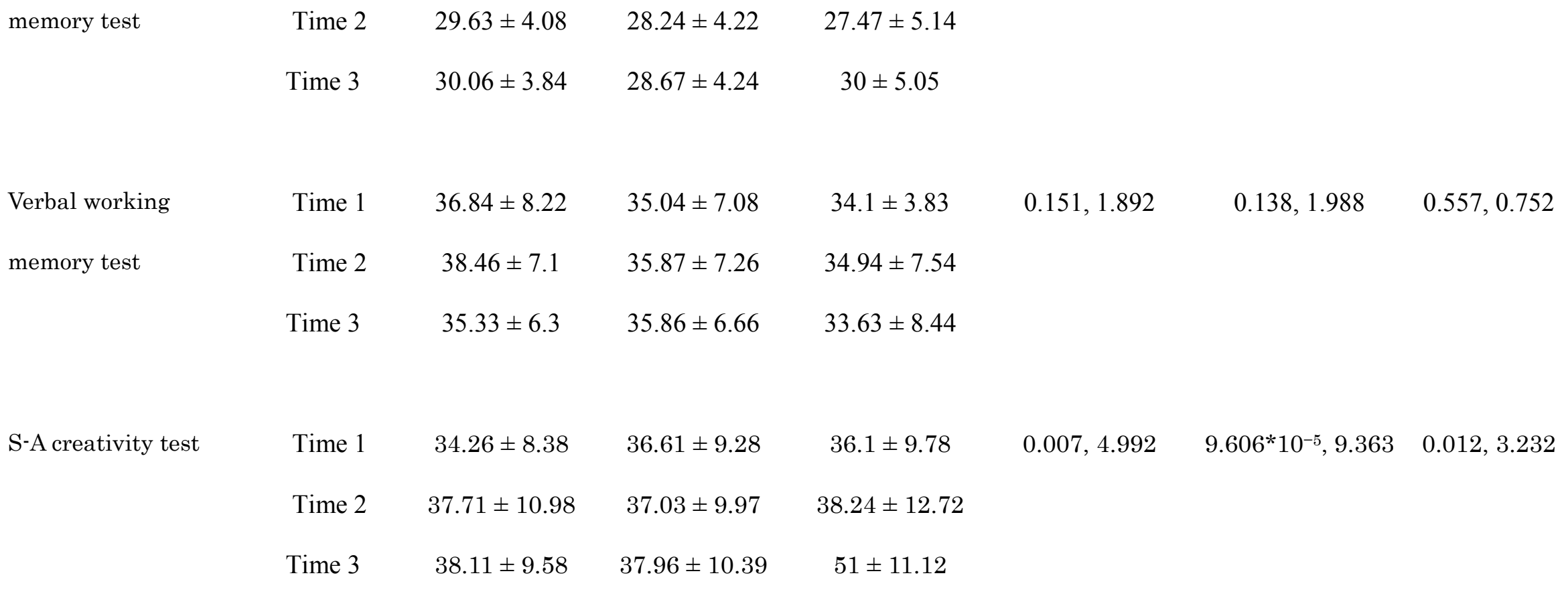

*For subjects of Time 1, the tests were performed in the morning (approximately 9:00-12:30), for subjects of Time 2, tests were assessed in the afternoon (approximately 13:15-16:45), and for subjects of Time 3, tests were performed in the evening (approximately 17:00-20:30). 
Table 4 Scores of personality measures or each chronotype and statistical values of the comparisons

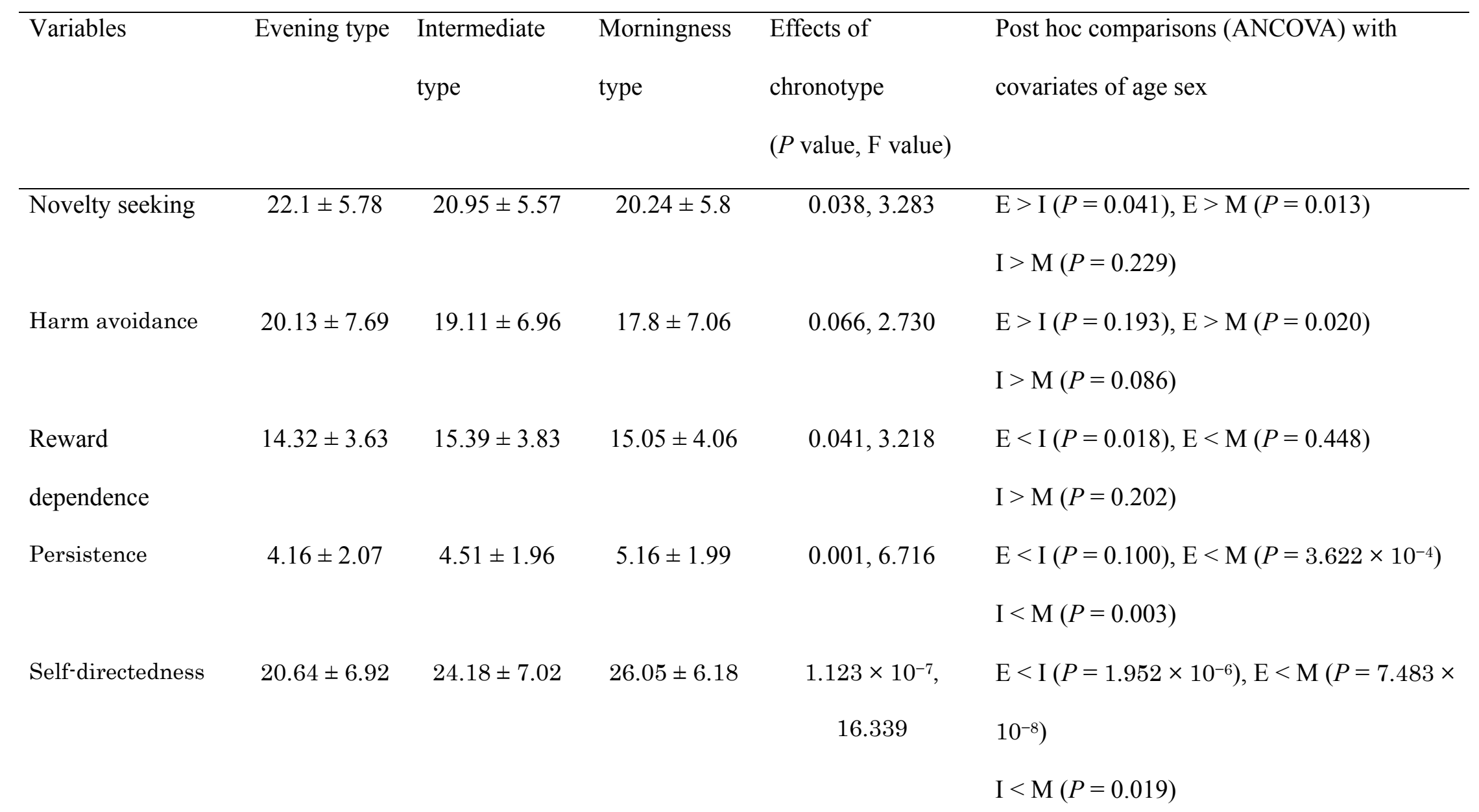




$\begin{array}{lccccc}\text { Cooperativeness } & 24.83 \pm 6.94 & 27.28 \pm 5.98 & 29.3 \pm 4.35 & 3.238 \times 10^{-6}, & \mathrm{E}<\mathrm{I}\left(P=2.136 \times 10^{-4}\right), \mathrm{E}<\mathrm{M}(P=6.557 \times \\ & & & 12.850 & \left.10^{-7}\right) \\ \text { Self-transcendence } & 10.02 \pm 5.1 & 10.97 \pm 5.26 & 12.09 \pm 5.22 & 0.033,3.413 & \mathrm{I}<\mathrm{M}(P=0.005) \\ & & & \mathrm{E}<\mathrm{I}(P=0.106), \mathrm{E}<\mathrm{M}(P=0.009) \\ \mathrm{I}<\mathrm{M}(P=0.075)\end{array}$


Table 5

Brain regions with significant correlations between rGMD and the MEQ score

\begin{tabular}{|c|c|c|c|c|c|c|c|c|}
\hline & & & & & & $\mathrm{T}$ & Corrected $P$ & \\
\hline & & & & & & score & value & Raw \\
\hline & & & & & & of the & (non-isotopic & cluster \\
\hline & & Brodman & & & & peak & adjusted & size \\
\hline Area & & n's area & $\mathrm{x}$ & $\mathrm{y}$ & $\mathrm{z}$ & voxel & cluster level) & $\left(\mathrm{mm}^{3}\right)$ \\
\hline & & nd the $\mathrm{Ml}$ & $\bar{Q}$ sco & (cova & Ca. Su & , age, an & RAPM and T & V scores) \\
\hline OFC & $\mathrm{R}$ & 11 & 31.5 & 43.5 & -27 & 4.17 & 0.003 & 1219 \\
\hline OFC & $\mathrm{L}$ & 11 & -27 & 39 & -30 & 4.06 & 0.007 & 2001 \\
\hline
\end{tabular}

Negative correlation between rGMD and MEQ score (covariates: sex, age, and RAPM and

TIV scores)

Precuneus/Cuneus/Superior

parietal lobule

$\begin{array}{llllll}7 / 19 & 7.5 & -73.5 & 24 & 5.50 & <0.001\end{array}$

11752

Superior parietal lobule/Middle

occipital lobe/Superior occipital
lobe
L
$7 / 19 \quad-21 \quad-69 \quad 46.5$
4.45
0.004
4907

Positive correlation between rGMD and MEQ score (covariates: sex, age, and TIV score)

$\begin{array}{lllllllll}\text { OFC } & \mathrm{R} & 11 & 31.5 & 43.5 & -27 & 4.25 & 0.002 & 1299 \\ \text { OFC } & \mathrm{L} & 11 & -27 & 39 & -30 & 4.03 & 0.009 & 1698\end{array}$

Negative correlation between rGMD and the MEQ score (covariates: sex, age, and TIV score)

$\begin{array}{lllllllll}\text { Precuneus/Cuneus } & & 7 / 19 & 7.5 & -73.5 & 24 & 5.48 & <0.001 & 11175 \\ \text { Superior parietal lobule/Middle } & \text { L } & 7 / 19 & -21 & -69 & 46.5 & 4.39 & 0.009 & 4266\end{array}$

Hikaru Takeuchi 
occipital lobe/Superior occipital

lobe

No other significant results were observed.

Hikaru Takeuchi 


\section{Figure legends}

Fig. 1. Distribution of the scores of MEQ scores in our sample.

Fig. 2. Anatomical correlates of morningness-eveningness. The results are presented on the skull-stripped image of the averaged normalized T1-weighted structural images of some of the subjects included in this study. Blue color represents the $\mathrm{T}$ score for the positive correlation between rGMD and eveningness (or less morningness and lower MEQ score). Red color represents the $\mathrm{T}$ score for the positive correlation between rGMD and morningness (higher MEQ score). rGMD was positively correlated with individual eveningness in a cluster that was mainly spread around the precuneus and in a cluster that was mainly spread around the left PPC. rGMD was positively correlated with individual morningness in a cluster in the lateral left OFC and in a cluster in the lateral right OFC. Results are shown with $P<0.05$, corrected for multiple comparisons at the cluster-level, with an underlying voxel-level of $P<0.001$, uncorrected.

Fig. 3. Anatomical correlates of morningness-eveningness. (a, b) The results are presented on a brain rendered in SPM. Blue areas represent regions showing a positive correlation between rGMD and eveningness (or less morningness and lower MEQ score). Red areas represent areas showing a positive correlation between rGMD and morningness (higher MEQ score). (a) Results are shown with $P<0.05$, corrected for multiple comparisons at the cluster level with an underlying voxel-level of $P<0.001$, uncorrected. (b) Results are shown with $P<0.05$, uncorrected.

Fig. 4. Anatomical correlates of morningness-eveningness. The results of analyses performed using images smoothed with 3-mm FWHM are presented on the skull-stripped image of the averaged normalized T1-weighted structural images of some of the subjects included in this study. Red color represents the $\mathrm{T}$ score for the positive 
correlation between rGMD and morningness (higher MEQ score). rGMD was positively correlated with individual morningness in bilateral peak coordinates that are likely to correspond to the suprachiasmatic nuclei and adjacent areas. Results are shown with $P<$ 0.05 , uncorrected. 
Fig. 1.

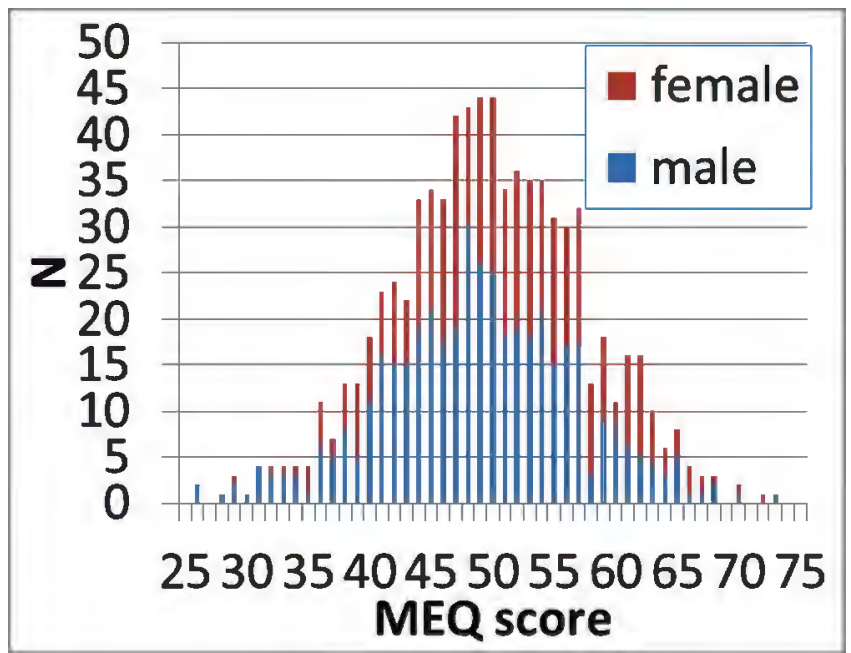

Hikaru Takeuchi 
Fig. 2.

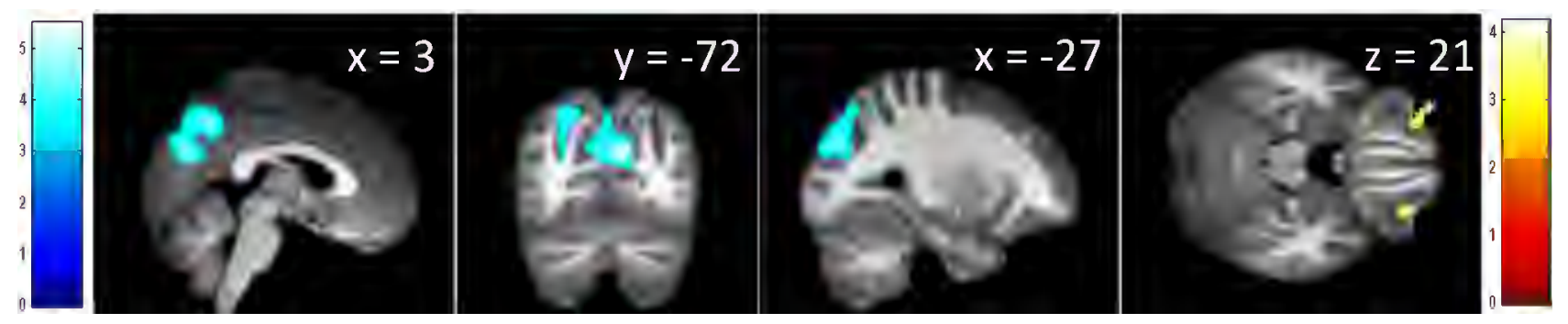


Fig. 3.

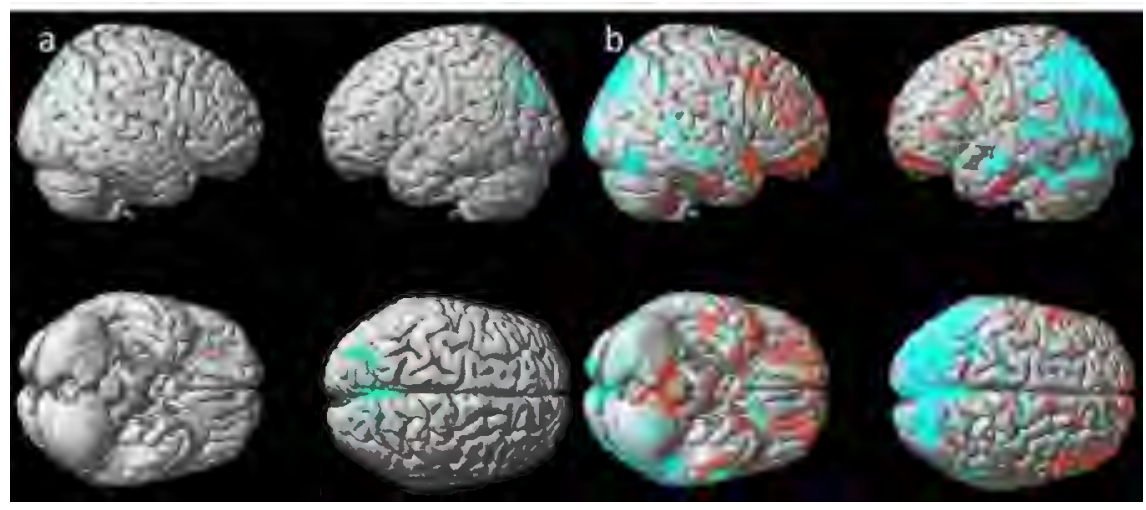

Hikaru Takeuchi 
Fig. 4.
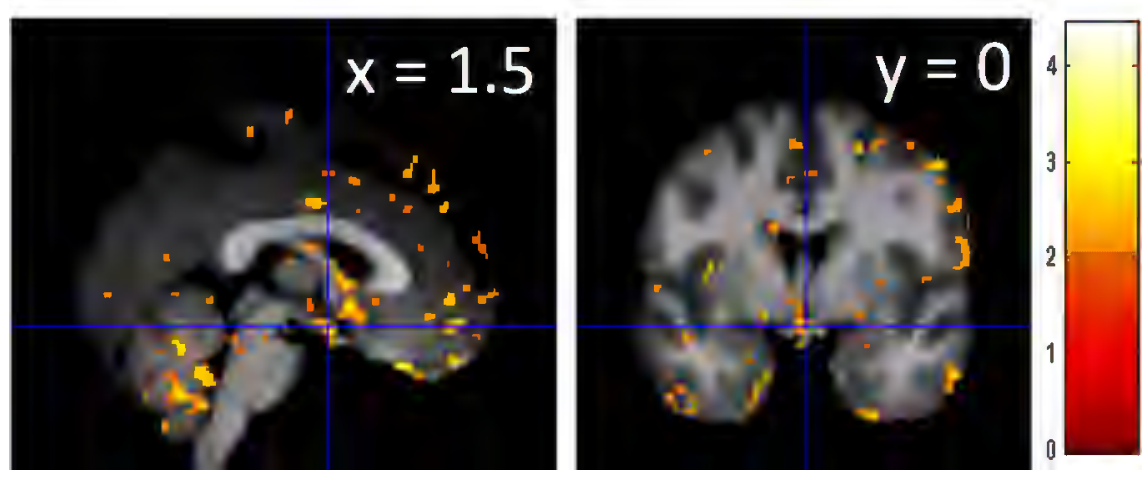